\title{
INSUFFICIENT GLUCURONIDE FORMATION IN THE NEWBORN AND ITS RELATIONSHIP TO THE PATHOGENESIS OF ICTERUS NEONATORUM
}

\author{
BY \\ M. VEST \\ From the Children's Hospital, University of Basel, Switzerland
}

(RECEIVED FOR PUBLICATION FEBRUARY 24, 1958)

In the last few years the pathogenesis of icterus neonatorum and kernikterus has aroused renewed interest (Napp and Plotz, 1949; Obrinsky, Allen and Anderson, 1954; Billing, Cole and Lathe, 1954; Meyer, 1956). The discovery by Schmid (1956) and Billing, Cole and Lathe (1957) that bilirubin is excreted in the bile as a glucuronide now makes it possible to reinvestigate this problem more specifically. The accumulation of bilirubin in the blood after birth suggests that the excretory capacity of the liver is inadequate. Such an inadequacy has been demonstrated only indirectly, either by the diminished ability of newborn and premature infants to excrete bromsulphalein dye (Mollison and Cutbush, 1949; Yudkin and Gellis, 1949; Obrinsky, Denley and Brauer, 1952; Perl, 1957) or by the fact that an inverse relationship exists between the amount of bile pigment in the meconium and the subsequent rise of the bilirubin in the serum (Ross, Waugh and Malloy, 1937; Fashena, 1948; Napp and Plotz, 1949; Vest, 1958).

It therefore seemed promising to investigate the glucuronic acid conjugating ability of the liver in newborn and premature infants. Storey and Dutton (1955) have demonstrated that the conjugation of substances like p-aminophenol, menthol and others with glucuronic acid is catalyzed by an enzyme system in the microsomes of the liver and requires uridine diphosphate glucuronic acid (UDPGA) as the glucuronide donor. The enzymatic formation of bilirubin glucuronyl seems to involve the same system (Schmid, Hammaker and Axelrod, 1957).

A diminished glucuronide synthesis in young animals as compared with adult animals was demonstrated in vitro with liver tissue from mice (Karunairatnam, Kerr and Levvy, 1949), rabbits (Hartiala and Pulkkinen, 1955) and rats (Vest, 1958). The purpose of this paper is to report the results of an investigation into the capacity of the liver of full term and premature infants to form glucuronides.

\section{Method}

We chose the substance acetanilide (Antifebrin) to assess glucuronide formation. After oral administration this compound is excreted to $80 \%$ as $\mathrm{N}$-acetyl-paminophenol-glucuronide, very little (about $4 \%$ ) appears as free $\mathrm{N}$-acetyl-p-aminophenol, and an insignificant part is de-acetylized in the body to aniline (Brodie and Axelrod, 1948a). This can give rise to the formation of methaemoglobin if an overdose is given. In the adult some $80 \%$ of the given amount of acetanilide is excreted in the urine within 24 hours. The dosage administered was $10 \mathrm{mg}$. $/ \mathrm{kg}$. body weight, an amount which does not produce any toxic effects. The acetanilide was given in milk or by stomach tube. The urine was collected for a period of 48 hours, but separately for each 24-hour period. Before and several hours after the administration of the acetanilide the methaemoglobin level in the blood was examined by the method of Evelyn and Malloy (1938). P-aminophenol (free and total conjugated) was determined by the method of Brodie and Axelrod (1948b). It was found necessary, however, to repeat the extraction with ether-isoamylalcohol as we were unable to recover all the p-aminophenol from urine in one step. Moreover, normal colour development with phenol and sodium hypobromite occurs only if the solution is distinctly alkaline. Therefore a surplus of sodium carbonate has to be added to the bromine water.

The method of Jendrassik and Gróf (1938) was used in the micro modification of With (1943) for the determination of bilirubin in the serum. The subjects investigated were 94 premature, full term infants and older children at the Children's Hospital, Basel.

\section{Results}

Fig. 1 shows the amount of p-aminophenol in the 24-hour urine expressed as a percentage of a given dose of acetanilide in relation to the age of the children. The graph includes the regression line for full term and premature infants. It can be seen 


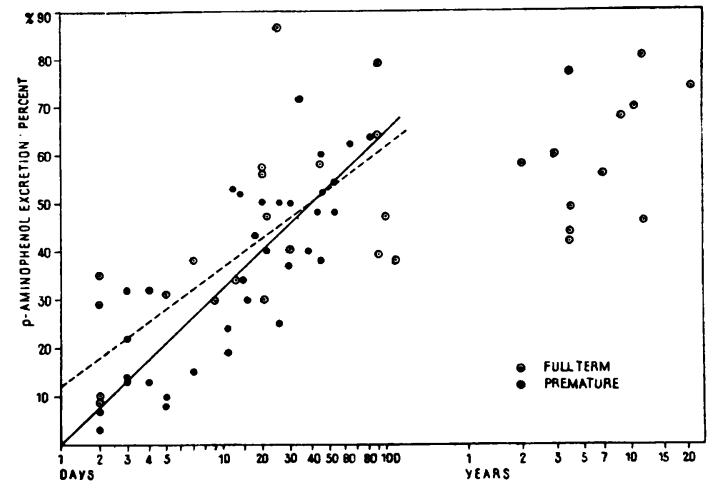

Fig. 1.-Excretion of p-aminophenol as glucuronide in 24 hours expressed as percentage of a given dose of acetanilide in relation to the age of the children.

that the excretion is much lower in newborn infants than in infancy and childhood and that premature infants have a still lower capacity to excrete a given amount of acetanilide. At the age of about 3 months the average excretion is not much below that of older children or of young adults and the difference between full term and premature infants can no longer be demonstrated. Free p-aminophenol was traceable in the urine of only a few cases and was generally well below $5 \%$ of the ingested acetanilide. Fig. 2 demonstrates how the ability to excrete acetanilide as glucuronide develops in the various premature and full term infants in the first 3 months of life. In almost every case this ability

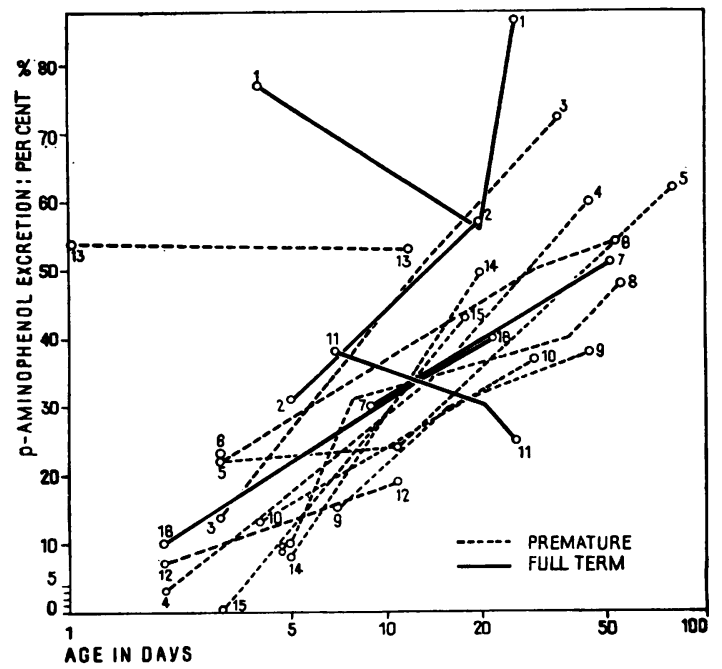

FIG. 2.-Increasing capacity of p-aminophenol-glucuronide excretion in individual premature and full term infants during the first 3 months of life. is very low in the beginning, but rises conspicuously within 10 to 20 days after birth. This ability immediately after birth is satisfactory only in a few infants (Cases 1 and 13). Figs. 3 and 4 are examples of the relationship which exists between the capacity of the newborn to eliminate Antifebrin as p-aminophenol-glucuronide and the height of the serum bilirubin concentration. An inverse relationship can be clearly demonstrated: with the increasing ability to form and excrete p-aminophenol-glucuronide the bilirubin level decreases to normal. Because of a rising bilirubin concentration in one infant an exchange transfusion was performed (Fig. 4) in order to remove bilirubin from the circulation, but with only temporary success. However, with increasing ability to conjugate glucuronic acid the bilirubin level falls steeply. One fact remains to be mentioned: Figs. 3 and 4 show two examples of the

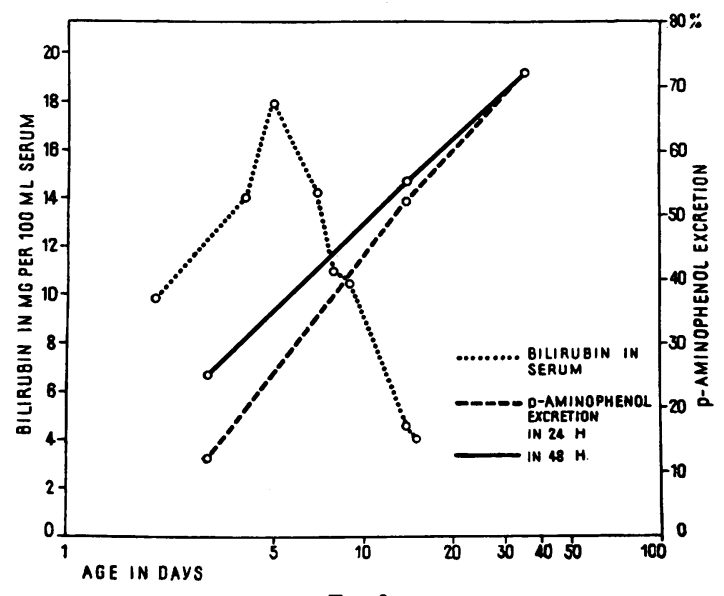

Fig. 3.

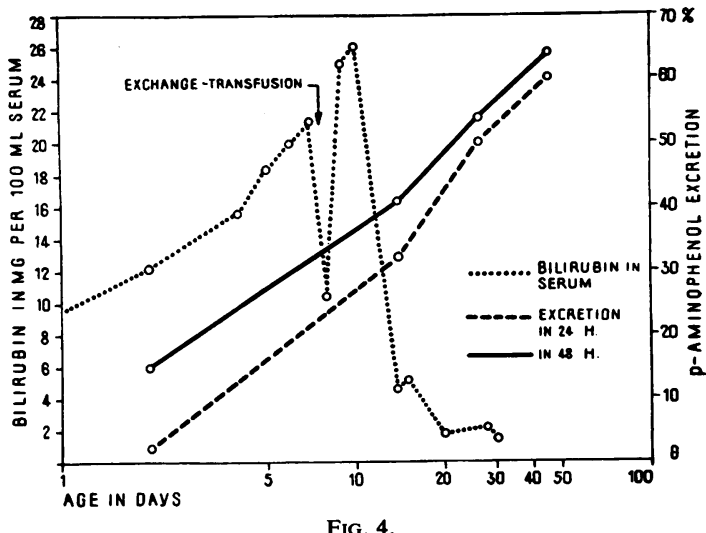

Figs. 3 and 4.-Premature infants. Examples of the relationship between the capacity to excrete acetanilide as p-aminophenolglucuronide and the height of the serum bilirubin concentration. 
amount of p-aminophenol excreted in 24 hours as well as the cumulative excretion in $\mathbf{4 8}$ hours. It is noteworthy that in infants tested in the first days after birth the excretion in the first 24 hours amounts to half or less of the 48-hour value. On the other hand, in infants aged over 15 to 30 days the difference between the 24-hour excretion and the cumulative excretion in $\mathbf{4 8}$ hours is small. Therefore in the first few days of life the excretion is not only diminished but also much delayed. Later in infancy and childhood, no p-aminophenol can generally be demonstrated in the second urine portion because all has already been eliminated in the first 24 or even 12 hours.

\section{Discussion}

The results shown demonstrate that the ability to excrete a given amount of acetanilide is greatly diminished in the newborn and premature infant and that the normal function develops within 3 months after birth. In the first few days after birth the excretion is also very much delayed.

There are two possibilities with regard to the underlying cause of this diminished excretion in the newborn. First, the excretory capacity of the kidneys might be insufficient or secondly, the liver might not be able to conjugate glucuronic acid. A simple calculation will demonstrate that the kidney is not at fault. Assuming a low absolute p-aminohippuric acid (PAH) clearance of $20 \mathrm{ml}$./min. in a newborn baby and a PAH blood level of $2.5 \mathrm{mg}$. per $100 \mathrm{ml}$., the kidney would eliminate $0.5 \mathrm{mg}$. PAH per minute from the plasma, i.e. $30 \mathrm{mg}$. in one hour. These figures are chosen deliberately on the low side of actual measurements and in most cases the kidney is able to clear two or three times as much. Since the molecular weights of PAH and p-aminophenolglucuronide are not very different, it is reasonable to assume that the kidney should be able to excrete at least $720 \mathrm{mg}$. of p-aminophenol-glucuronide in 24 hours. We have seen that the newborn baby is unable to excrete a dose of only $10 \mathrm{mg}$. acetanilide per $1 \mathrm{~kg}$. body weight within this length of time. There can be no doubt that the excretory power of the kidney in the newborn would be adequate to meet this demand. One must conclude, therefore, that the liver of the newborn infant is unable to conjugate a sufficient amount of p-aminophenol with glucuronic acid. It must be remembered that this conjugation is necessary in order to make it possible for the kidney to excrete p-aminophenol. The same enzyme system is responsible for the conjugation of bilirubin to bilirubin glucuronide. Therefore the investigations described in this paper gave a direct indication of the cause of increased bilirubin accumulation in the newborn and of the patho- genesis of icterus neonatorum. Generally the bilirubin concentration in premature infants is high after birth. Concurrently these infants have also the lowest p-aminophenol excretion. This corresponds well with the fact that premature infants have the lowest content of bile pigment in meconium (Ylppö, 1913; Vest, 1958). As we have briefly mentioned, other functions of the liver are poorly developed in the newborn as well, e.g. the ability to excrete bromsulphalein or to conjugate benzoic acid with glycin or the formation of prothrombin and proconvertin (Loeliger and Koller, 1952; van Creveld, Paullsen, Ens, van der Meij, Versteegh and Versteegh, 1954; Vest and Meier, 1957).

In contrast with the congenital familial nonhaemolytic icterus (Crigler and Najjar, 1952) in which an isolated defect of the glucuronic acid conjugating system exists (Schmid, Axelrod, Hammaker and Rosenthal, 1957) there is a deficiency in more than one metabolic liver function in the newborn baby. One of these, the insufficiency of the glucuronic acid conjugating system, accounts for the hyperbilirubinemia and gives rise to icterus of the newborn.

\section{Summary}

The capacity of the liver to form glucuronides was tested in full term and premature infants by administration of acetanilide in a dosage of $10 \mathrm{mg} . / \mathrm{kg}$. body weight and by measurement of the amount of p-aminophenol-glucuronide in the urine. Adults and older children are able to excrete about $80 \%$ of this value in 24 hours or less, whereas newborn and especially premature infants only eliminate a few $\%$ in 24 hours. Even in 48 hours the total excretion in newborn infants amounts to only about $10 \%$ or less. Within the first weeks of life the power to conjugate glucuronic acid steadily increases and by the age of 3 months normal function is generally reached.

There exists an inverse relationship between the ability to form glucuronides and the height of the bilirubin concentration in the serum. As the capacity of the liver to form glucuronides increases the serum bilirubin level begins to fall. It is concluded that this insufficiency in the formation of glucuronides by the liver might be regarded as the underlying cause of icterus neonatorum.

\section{REFERENCES}

Billing, B. H., Cole, P. G. and Lathe, G. H. (1954). Brit. med. J. 2,1263 .

__, 2, (1957). Biochem. J., 65, 774.

Brodie, B. B. and Axelrod, J. (1948a). J. Pharmacol., 94, 29.

, (1948b). Ibid., 94, 22.

Creveld, S. van, Paullsen, M. M. P., Ens, J. C., van der Meij, C. A. M.,

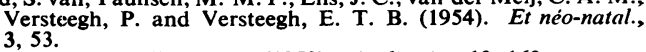

Crigler, J. F. and Najjar, V. A. (1952). Pediatrics, 10, 169.

Evelyn, K. A. and Malloy, H. T. (1938). J. biol. Chem., 126, 655. Fashena, G. J. (1948). Amer. J. Dis. Child., 76, 196. 
Hartiala, K. J. V. and Pulkkinen, M. (1955). Ann. Med. exp. Biol. Fenn., 33, 246.

Jendrassik, L. and Gróf, P. (1938). Biochem. Z., 297, 81.

Karunairatnam, M. C., Kerr, L. M. H. and Levvy, G. A. (1949).

Biochem. J., 45, 496. (1952). Acta haemat. (Basel), 7, 157.
Loeliger, A. and Koller, F.

Meyer, T. C. (1956). Arch. Dis. Childh., 31, 75.

Mollison, P. L. and Cutbush, M. (1949). Ibid., 24, 7.

Napp, J. H. and Plotz, J. (1949). Arch. Gynäk., 176, 781.

Obrinsky, W. Allen, E. L. and Anderson, E. E. (1954). Amer. J. Dis. Child., 87, 305.

- , Denley, M. L. and Brauer, R. W. (1952). Pediatrics, 9, 421.

Perl, E. (1957). Schweiz. med. Wschr., 87, 334.
Ross, S. G., Waugh, T. R. and Malloy, H. T. (1937). J. Pediat.,

Schmid, R. (1956). Science, 124, 76.

Hammaker, L. and Axelrod, J. (1957). Arch. Biochem., 70, 285.

Axelrod, J., Hammaker, L. and Rosenthal, I. M. (1957). $J$ clin. Invest., 36, 927.

Storey, I. D. E. and Dutton, G. J. (1955). Biochem. J., 59, 279.

Vest, M. (1958). Physiologie und Pathologie des Neugeborenenicterus. In press. S. Karger. Basel and New York.

and Meier, W. (1957). Ann. paediat. (Basel), 189, 282.

With, T. K. (1943). Hoppe-Seyl. Z. physiol. Chem., 278, 120.

Ylppö, A. (1913). Z: Kinderheilk.. 9, 208.

Yudkin, S. and Gellis, S. S. (1949). Arch. Dis. Childh., 24, 12. 